\title{
CAMBIOS EN LOS USOS Y CUBIERTAS DEL SUELO Y LOS EFECTOS EN LA VULNERABILIDAD EN LAS COMARCAS DE MONTAÑ A DE CATALUÑA. DEL ROL DEL FUEGO COMO HERRAMIENTA DE GESTIÓN A LOS INCENDIOS COMO
} AMENAZA

\section{Land use and land cover change and the effects on vulnerability to forest fire of counties in the mountains of Catalonia: from managing the land to managing a threat}

\author{
A. Badia, A. Pèlachs, A. Vera, A.F. Tulla \& J.M. Soriano \\ Departamento de Geografía, Universidad Autònoma de Barcelona. ES-08193, Bellaterra (Cerdanyola del Vallès). anna.badia@uab.cat
}

Recibido: 30-04-2013. Aceptado: 20-07-2013. Fecha de publicación on-line: 08/07/2014

Citation / Cómo citar este artículo: Badia, A., Pèlachs, A., Vera, A., Tulla, A. F. \& Soriano, J. J. (2014). Cambios en los usos y cubiertas del suelo y los efectos en la vulnerabilidad en las comarcas de montaña de Cataluña. Del rol del fuego como herramienta de gestión a los incendios como amenaza. Pirineos, 169, e001. doi: http://dx.doi.org/10.3989/Pirineos.2014.169001

\begin{abstract}
RESUMEN: En los Pirineos el fuego ha sido una de las herramientas más antiguas y eficientes de la historia de la gestión de los usos del suelo y ha contribuido a dar forma a un paisaje de una gran diversidad. La acción humana sobre la cubierta del suelo ha introducido algunas modificaciones, de forma que los incendios forestales han dejado de ser un proceso más del sistema natural para convertirse en una grave amenaza para los ecosistemas y para la sociedad. Utilizando técnicas SIG y análisis estadístico se cuantifican los cambios en las cubiertas del suelo y se hace una diagnosis de los puntos de ignición ocurridos en las comarcas de montaña del Pirineo catalán durante el periodo 19932007, en función de la estacionalidad y algunas características del territorio como la altitud, la pendiente y la orientación. De esta forma se pretende aportar argumentos que ayuden a dar respuesta a la pregunta ¿qué ha cambiado en el Pirineo para que los incendios actualmente constituyan un riesgo? Los resultados indican que: a) los cambios en las cubiertas del suelo tienden al recubrimiento arbóreo y a un paisaje forestal más homogéneo; b) la mayoría de incendios que queman mayor superfície empiezan en zonas de matorral y bosque claro, lo cual supone una muestra de la tendencia a la transición forestal después del abandono de las actividades tradicionales en las áreas de montaña c) los incendios se concentran en invierno y se localizan en zonas accesibles.
\end{abstract}

PALABRAS CLAVE: Usos y cubiertas del suelo; transición forestal; puntos de ignición; Pirineos

ABSTRACT: Fire is one of the oldest and most efficient tools for managing land use in the Pyrenees and has contributed to shaping a landscape of great cultural and ecological diversity. Human actions affecting land cover have introduced certain changes that affect the role and our perception of forest fires, converting them from one of the normal processes of nature into a serious threat to ecosystems and to society. This study addresses the question: what specific changes in the Pyrenees have led to the current perception of forest fire as a risk or threat? Using GIS and statistical analysis, 
we conducted a quantitative assessment of land cover changes and we reviewed the forest fires that have occurred in the counties (comarques) of the Catalan Pyrenees between 1993-2007, in terms of seasonality and some characteristics of the territory as altitude, slope and orientation. The results shows that: a) land cover change tend to forestry and a more homogeneous landscape; b) most surface burned occurred in bush and clear forest, what is a sign of the trend of forest transition; c) there is a concentration of fires in winter ahead of summer and are located in accessible areas.

KEYWORDS: Land use and land cover; forest transition; ignition points; Pyrenees

\section{Introducción}

Tradicionalmente, el fuego en las zonas de montaña de la cuenca mediterránea ha formado parte activa de las actividades agrosilvopastoriles y es por ello que en este contexto la lucha contra los incendios forestales no ha sido nunca una prioridad. Desde el Neolítico los incendios han sido una de las herramientas de gestión del territorio y, si bien es cierto que estos han causado algunas perturbaciones devastadoras, el fuego ha sido y es un elemento regulador del bosque en el mundo rural, usado muy a menudo para la creación y/o recuperación de zonas agrícolas (campos de cultivo y/o de pastos; Vélez, 1986; Pyne, 1996; Cunill et al., 2013). No obstante, en la actualidad el fuego parece ser una amenaza, ¿qué ha cambiado en el Pirineo para que los incendios actualmente constituyan una amenaza? Hoy en día hay una coincidencia en considerar que los incendios forestales se comportan de manera distinta a cualquier otro momento de la historia (Asociación Mundial del Fuego, 2004); ello es debido en gran medida a los cambios en los usos y cubiertas del suelo ocurridos a partir de la segunda mitad del siglo XX y que explican la denominada transición forestal (proceso de forestación a consecuencia del abandono de los usos agrarios tradicionales).

En esta investigación se hace una diagnosis del proceso de cambios en los usos ocurridos en las denominadas comarcas de montaña de Cataluña (Llei 2/1983) durante el periodo $1993-2005^{1}$ y se analiza cómo estos cambios favorecen el incremento de la vulnerabilidad frente a los incendios forestales. Paralelamente, se estudia la incidencia y tipología de los incendios a partir de la frecuencia de igniciones durante el período 1995 $2008^{2}$ y su relación con la estacionalidad y las características territoriales, con el fin de valorar la tendencia de los cambios que se están produciendo. La hipótesis de trabajo parte de la premisa que los incendios en el Pirineo catalán tienen unas características concretas que los hacen distintos al resto de comarcas de Cataluña, especialmente en cuanto a la estacionalidad, y las características físicas del territorio como las altitudes, la orientación y las cubiertas del suelo; además determinan una mayor presencia de incendios en determinadas altitudes, orientaciones y cubiertas del suelo.

\subsection{Los cambios económicos, sociales y culturales como motor del cambio en los usos y cubiertas del suelo}

La pérdida de rentabilidad económica de las actividades agrícolas y ganaderas del Pirineo ha comportado un proceso de cambios drásticos en los usos y cubiertas del suelo. La substitución de un sistema por otro ha modificado la función socio-económica del territorio y consecuentemente los usos del suelo y la dinámica de la vegetación y del paisaje (Lasanta et al., 2005; Lasanta et al., 2006). Uno de los impactos más importantes que apunta el Land Use Land Cover Change (LUCC) es la conversión de suelo productivo a no productivo, comportando un crecimiento y densificación de la masa forestal en zonas tradicionalmente ocupadas por campos de cultivo, pastos o bosque poco denso. Al aumentar la biomasa disponible, la vulnerabilidad del territorio se incrementa y al abandonar el territorio se pierde valor cultural en la gestión y el medio se percibe de forma distinta. Tradicionalmente ha habido un gran número de áreas con una función social y ecológica muy importante, como las zonas de montaña, que se muestran especialmente vulnerables al cambio global (Schröter et al., 2005). En este sentido, el abandono de la agricultura favorece los estadios de transición forestal, pasando de un territorio gestionado, y por lo tanto organizado, a un proceso de colonización de especies más inflamables que derivan a una homogeneización del paisaje. El estudio de los cambios de los usos y las cubiertas del suelo se convierte en un componente fundamental en el estudio del cambio ambiental global y la sostenibilidad (Turner et al., 2007).

El Convenio Europeo del Paisaje (CEP), que entró en vigor en marzo de 2004, promueve la protección, gestión y ordenación de los paisajes europeos. Define el concepto de paisaje como la "parte del territorio tal como la percibe la población, cuyo carácter resulta de la acción de los factores naturales y/o humanos y de las relaciones que se establecen entre ellos" y en referencia a la protección del paisaje incluye "las acciones de conservación y de mantenimiento de los rasgos significativos o característicos de un paisaje, justificadas por el valor patrimonial que se deriva de su configuración natural y/o de la intervención humana" (Council of Eu-

\footnotetext{
${ }^{1}$ Los cambios se analizan a partir de la disponibilidad del mapa de cubiertas de suelo del año 1993 y del año $2005-07$. http://www.creaf.uab.es/mcsc/.

${ }^{2}$ El periodo disponible de datos sobre incendios abarca desde 1995 a 2008.
} 
rope, The European Landscape Convention), por lo que hay un interés en la protección del paisaje a través del desarrollo local, regional e internacional y mediante las regulaciones y estrategias con el fin de preservar la calidad del paisaje en Europa.

En relación a este interés en la preservación de los valores del paisaje, los cambios en los usos y las cubiertas del suelo se convierten en uno de los principales focos de atención: toda gestión y planificación que pretenda evitar o solucionar impactos en el medio ambiente requiere un análisis de la evolución de los usos y las cubiertas del suelo y los cambios en la estructura del paisaje. En este sentido, el proyecto internacional LUCC inició un interesante debate sobre estos cambios a partir del cambio global, refiriéndose a aquellas modificaciones humanas que se desarrollan sobre la superficie de la tierra.

\subsection{La Transición Forestal}

El año 1990 Mather propuso denominar "Transición Forestal" (TF) al proceso de forestación que tuvo lugar en Escocia a partir de la segunda mitad del siglo XX, después de un período muy largo de deforestación por la expansión de la agricultura (Rudel et al., 2005; Rudel et al., 2010; Lambin \& Meyfroidt, 2010). Antrop (2006) advierte que los cambios en el paisaje empiezan a ser devastadores y muchos de sus valores se están perdiendo irreversiblemente, creándose nuevos paisajes. En este contexto, el concepto TF resulta muy útil para explicar las relaciones históricas entre el bosque y la sociedad, ya que explica el paso de la deforestación a la reforestación. ${ }^{3}$ Para Mather, la urbanización y la industrialización inducen primero a una reducción prolongada de la extensión de los bosques, y luego a una reforestación parcial. Apuntan dos formas de transición: la primera, el "camino del desarrollo económico", cuando los agricultores y ganaderos van abandonando la tierra porque los trabajos no vinculados a este sector se pagan mejor, convirtiendo las zonas agrícolas en terrenos forestales por el abandono de cultivos y pastos. La segunda, la pérdida de bosques durante la expansión agrícola, la cual supuso la aplicación de políticas compensatorias, ya que la escasez de bosques comportó la importación de madera a un precio muy alto, lo que motivó que se dieran subvenciones para la replantación de árboles, motivo por el cual los propietarios sustituyeron los campos de cereal de nuevo por bosques (Rudel et al., 2005; Rudel et al., 2010).

La primera forma de TF expuesta por Mathers puede servir perfectamente para explicar los cambios en los usos y cubiertas del suelo en el Pirineo, a pesar de que algunos autores alertan de la dificultad de aplicar la TF a escala local y regional (Turner \& Robbins, 2008). Es en el contexto de esta transición donde se sitúa la problemática de los incendios forestales, al explicar el paso de un uso agrícola a arbustivo y de un uso arbustivo a bosque por el abandono de la actividad dada la baja rentabilidad económica (Benayas et al., 2007; Millington, 2007; Moreira et al., 2011). Además, a la TF deberíamos añadir un incremento de la presión humana relacionado con el proceso de urbanización (segundas residencias, estaciones de esquí alpino, etc.), importante a partir de la década 1980-89 en el Pirineo, el cual también ha contribuido a incrementar el riesgo de incendios (Vera et al., 2011).

\subsection{Vulnerabilidad del territorio}

La investigación en vulnerabilidad tiende a enfatizar en las amenazas y en la capacidad de adaptación de la sociedad. Analiza básicamente la dinámica de los subsistemas humanos, especialmente el rol de la globalización económica en el momento que afectan a los seres humanos: vulnerabilidad como potencial de pérdidas en un lugar concreto. Hewitt (1997) enumera los siguientes aspectos relacionados con la vulnerabilidad al riesgo: a) exposición a fenómenos peligrosos (estar en el lugar equivocado en el momento equivocado); b) debilidad: la predisposición de determinados grupos humanos, actividades económicas, comunidades o territorios a sufrir daños; c) falta de protección contra fenómenos peligrosos; d) desventaja: falta de recursos para incidir en las causas del riesgo y dar respuesta a los peligros; e) falta de resiliencia: capacidad limitada o inexistente para evitar los efectos de un desastre o de recuperarse de este desastre a posteriori; f) falta de poder político: incapacidad de influir sobre las medidas de seguridad o de adquirir medios de protección o recursos para la recuperación.

La vulnerabilidad y la resiliencia son dos aproximaciones para entender la respuesta de los sistemas y actores a los cambios en la estructura del territorio. La necesidad de entender las causas de la vulnerabilidad, la escala en la que ocurre y los principales actores involucrados para identificar oportunidades para la reducción del riesgo, cómo afrontarlo y cómo adaptarse (Miller et al., 2010), pasa inevitablemente por el análisis de los cambios en los usos y las cubiertas del suelo. Entendiendo la dinámica de los cambios se aprende a convivir con ellos y se desarrolla la capacidad de hacer frente al riesgo. En este artículo entendemos por vulnerabilidad la exposición del territorio al riesgo como consecuencia de los cambios en los usos y cubiertas del suelo. No se trata de analizar el propio riesgo como probabilidad de que se produzca un incendio en un lugar determinado a partir de unas condiciones determinadas y que este se propague, sino de evaluar las dinámicas de los cambios que hacen que el territorio pirenai-

\footnotetext{
${ }^{3}$ A pesar que es un proceso que puede generalizarse al resto de Europa, algunas zonas de Norte América, y Asia más recientemente, esta teoría ha recibido algunas críticas (Chowdhury \& Moran, 2012) que enfatizan en el hecho de que el proceso de reforestación no se puede generalizar debido a que a escala global continúa el proceso de deforestación.
} 


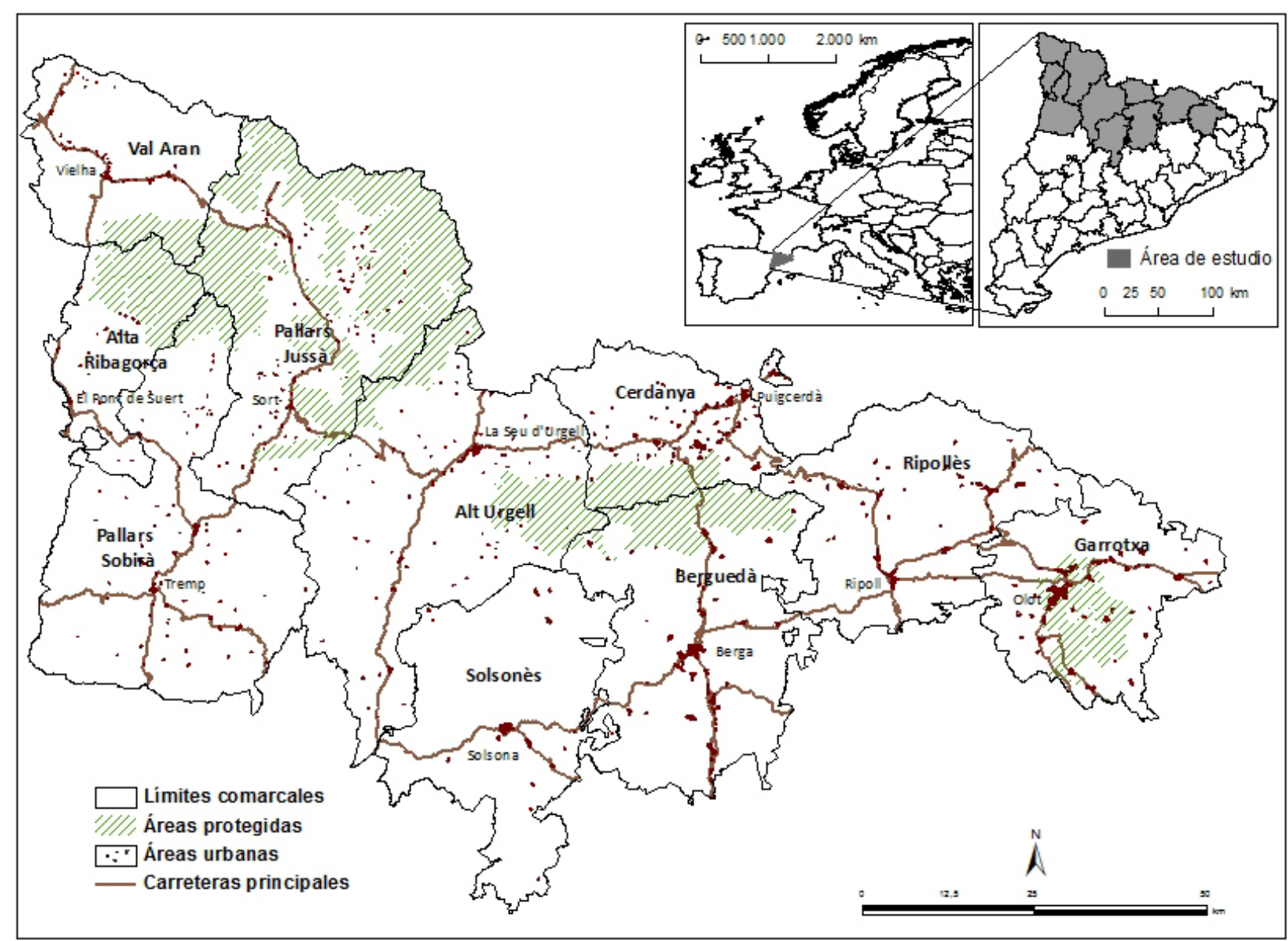

Figura 1: Área de estudio. Fuente: Elaboración propia. Figure 1: Study area.

co sea más vulnerable a los incendios, y como complemento al análisis de los cambios en los usos y cubiertas del suelo, analizamos las características de los incendios durante los últimos 15 años.

\section{2. Área de estudio}

La investigación se ha realizado en las comarcas de montaña catalanas definidas por la Llei 2/1983 d'Alta Muntanya: l'Alt Urgell, l'Alta Ribagorça, la Cerdanya, el Pallars Jussà, el Pallars Sobirà, el Ripollès, la Vall d'Aran, el Berguedà, el Solsonès i la Garrotxa (Figura 1). Aunque hay diferencias significativas entre ellas, tanto físicamente como socioeconómicamente, en este trabajo se ha optado por considerar estrictamente las comarcas que integran dicha ley. Se trata de un área de aproximadamente 9.000 $\mathrm{km}^{2}$, el $30 \%$ de la superficie total de Cataluña, con una altitud que se sitúa aproximadamente entre los 100 y los 3000 metros. Las cinco cubiertas predominantes son: el pinar, con aproximadamente el $25 \%$ de la superfície(Pinus sylvestris, Pinus nigra y Pinus uncinata); el matorral, con el $15 \%$; los prados y herbazales de alta montaña, con un $9 \%$; los robledos (Quercus sp.) con más del 8\%; y el enci- nar (Quercus ilex) con el 6\% (MCSC, 2005-07). La riqueza natural de las comarcas de montaña ha motivado un interés proteccionista por parte de la administración, no en vano el $17 \%$ de este territorio está bajo alguna figura de protección (Parque Nacional, Parque Natural, red Natura 2000, etc.).

Las condiciones climáticas aparecen a menudo como causas explicativas de los incendios. Las comarcas de montaña de los Pirineos forman parte en general del dominio climático mediterráneo, aunque dentro de una franja de transición climática con características oceánicas. La compleja orografía de este sector determina que las temperaturas medias oscilen entre $\operatorname{los} 4^{\circ} \mathrm{C}$ en alta montaña y los $12^{\circ} \mathrm{C}$ en los valles y zonas de menor altitud (Ninyerola et al., 2000).

\section{Materiales y métodos}

\subsection{Bases de datos}

- Puntos de ignición. Las bases cartográficas de los incendios provienen de la Generalitat de Cataluña, que dispone de una extensa base de datos en cuanto 
a incendios forestales. Desde el año 1968 se recopila información general de los incendios, y desde el año 1987 se anotan las coordenadas de los puntos de ignición, pero no es hasta el año 1995 cuando se hace una recogida sistemática y homogénea de todos los incendios ocurridos en territorio catalán. Es por ello que el análisis de los incendios en el Pirineo catalán abarcará el período 1995-2008. Asociada a cada incendio hay información de gran interés como el día del incendio, la comarca donde tuvo lugar, la superficie quemada (diferenciado según si se ha quemado forestal -arbolado, no arbolado, pastos-, y no forestal), etc. que permite caracterizar mejor los incendios de manera que es posible saber la estacionalidad, si hay comarcas más afectadas que otras, tipo de hectáreas quemadas, etc. Es importante resaltar que en este estudio se considera especialmente los puntos de ignición y queda en un segundo plano la superfície quemada, debido a que esta información es la asociada a las coordenadas del incendio y no se dispone del perímetro de los distintos incendios. ${ }^{4}$

- Mapa de Cubiertas del Suelo de Cataluña (MCSC) necesario para el análisis de los cambios, el cual se ha extraído del servidor de mapas del CREAF. ${ }^{5}$ El MCSC ráster ${ }^{6}$ presenta tres ediciones que, a parte de tener diferente fecha en su imagen base ( $1^{\mathrm{a}}$ edición, 1993; $2^{\mathrm{a}}$ edición, 2000-2002; $3^{\mathrm{a}}$ edición, 2005-2007), presentan diferencias en las características de la imagen base: píxel de 2,5 m para la $1^{\mathrm{a}}$ edición, y píxel de $0,5 \mathrm{~m}$ para las dos posteriores (se ha optado por una resolución de 2,5 metros, por lo que el mapa de cubiertas del año 2005-07 se ha densificado a 2,5 metros). Hay que añadir que la leyenda de cada edición también es distinta, siendo de más detalle y con nuevas categorías en las ediciones posteriores. Sin embargo, en la confección del Mapa de cubiertas, siempre se ha procurado mantener la comparabilidad entre ediciones (CREAF, 2010).

- Modelo Digital del Terreno (MDT), disponible en la página web de la Generalitat de Cataluña con una resolución de $20 \mathrm{~m}$, a partir del cual se han calculado los derivados (orientación y pendiente) y así se han tipificado los incendios según la altitud, la pendiente y la orientación donde tuvieron lugar.

\subsection{Método}

La metodología utilizada en esta investigación se fundamenta en el uso de los Sistemas de Información Geográfica (SIG) y el análisis estadístico mediante la prueba de ji cuadrado $\left(\chi^{2}\right)$. Consta de tres fases: (1) captura de datos, (2) análisis espacial para interrelacionar las distintas bases cartográficas y (3) cálculo de ji cuadrado.

El análisis de los cambios en las cubiertas ha sido el primer paso para cuantificar y evaluar la dinámica de los cambios en el territorio. En el análisis de los cambios en los usos y cubiertas del suelo del Pirineo se han utilizado los mapas de los años 1993 y 2005-07. Siguiendo el documento del CREAF (2010) se han homogeneizado las dos bases tanto en resolución (1993 resolución de 2,5 m y 2005-07 resolución de 0,5 m) como de número de categorías, a partir de una reclasificación de las dos leyendas, con el fin de hacerlas comparables. Se han obtenido dos mapas de diez categorías (Bosque denso, Bosque claro, Matorral, Prados y herbazales, Zonas quemadas, Cultivos, Zonas denudadas, Aguas, Zonas urbanizadas, Vías comunicación). ${ }^{8}$ En una segunda fase del análisis se ha reclasificado el mapa fruto de la combinación analítica de capas en cuatro categorías para una mejor interpretación (bosque denso, matorral/bosque claro, pastos y cultivos).

A partir del MDT de Cataluña con una resolución de 20 metros se ha extraído el mapa de orientaciones y de pendientes.

El hecho de disponer de las coordenadas de los incendios ha permitido caracterizarlos en relación a las características del territorio a partir de repetidas combinaciones analíticas de capas, es decir la superposición espacial de la capa de puntos de ignición con cada una de las capas territoriales dando como resultado nuevas capas con la información de las distintas capas superpuestas. Con la finalidad de caracterizar los incendios según las cubiertas del suelo durante el período de 15 años, y dado que los mapas de cubiertas corresponden a dos periodos de tiempo distintos (1993 y 2005-07), se ha optado por caracterizar los incendios a partir del mapa resultado de la superposición espacial. De esta forma se asocia a cada incendio la cubierta a que correspondía el año 1993 y el año 2005-07.

La distribución de frecuencias observadas y esperadas de los incendios hace posible el cálculo del $\chi^{2}$ que relaciona las distintas variables con el porcentaje de incendios. El test de $\chi^{2}$ compara una muestra categórica de frecuencias observadas con una de muestra predeterminada, es decir, las frecuencias esperadas. Las frecuencias esperadas se calculan en fución del porcentaje de superficie en cada intervalo (establecido préviamente por la distribución de frecuencias observadas), a partir del cual se halla la proporción correspondiente de incendios. Las cinco variables de análisis (altitud, orientación,

\footnotetext{
${ }^{4}$ En todos los gráficos que se verán a lo largo del artículo, la superficie se corresponde con la comarca en la cual se localiza el punto de ignición.

${ }^{5}$ Centre de Recerca i Aplicacions Forestals (CREAF), http://www.creaf.uab.es/mcsc/.

${ }^{6}$ Las tres ediciones disponibles del MCSC las podemos descargar en formato ráster y vectorial.

${ }^{7}$ Estos datos y los referentes a otras bases de datos procedentes de la Generalitat de Catalunya son accesibles desde la página web www.gencat.cat.

${ }^{8}$ En la página web del MCSC hay una descripción detallada de cada una de las categorías www.creaf.uab.cat/mcsc.
} 
pendiente, cubiertas del suelo y estacionalidad) se han analizado de forma independiente comparando para cada variable la distribución de frecuencias observadas con la distribución de frecuencias esperadas. Para el cálculo, las variables continuas, altitud y pendiente, se han reclasificado estableciendo un máximo de cuatro categorías; la variable orientación tiene ocho categorías, las cubiertas del suelo se han agrupado en cuatro y la estacionalidad por definición tiene cuatro categorías. Los valores esperados se calculan en función del porcentaje de la superficie del territorio que queda en cada intervalo establecido por la distribución de frecuencias observadas y se calcula la proporción correspondiente de incendios en función de la distribución de incendios observados en cada intervalo. El resultado de $\chi^{2}$ de cada variable se ha comparado con un valor crítico calculado a partir de los grados de libertad de cada variable (número de casos o categorías menos el número de variables, en nuestro análisis una) y un nivel de significación constante $(0,01)$. La validación de la hipótesis de investigación se ha llevado a cabo cuando el valor de $\chi^{2}$ es superior al valor crítico. En caso contrario se ha rechazado la hipótesis de investigación. La validación de la hipótesis de investigación se realiza a partir de la comparación entre el valor resultante de $\chi^{2}$ y el valor crítico de $\chi^{2}$.

\section{Resultados y discusión}

\subsection{Análisis descriptivo de los incendios en las comarcas de montaña}

Los incendios en Cataluña se han convertido en un fenómeno ambiental de gran magnitud al que se destinan grandes recursos humanos y económicos. Durante el periodo 1986-2009 hubo más de 16.000 incendios con una superficie total quemada de aproximadamente 240.000 ha, en la que Plana (2011) establece distintas unidades forestales de entre las cuales cabe destacar la de los Pirineos. Precisamente esta unidad es la que sufre un menor impacto tanto de incendios como de superficie quemada en comparación al total de Cataluña, con 1.200 incendios, el 7,5\% de Cataluña y 8.000 ha quemadas, es decir el 3,3\% del total para este periodo. Aunque la delimitación de Eduard Plana no coincide con las comarcas de montaña definidas por la ley, las cuales son objeto de nuestro estudio, esta delimitación resulta útil como indicador. A pesar que los números indican un bajo impacto de los incendios en las comarcas pirenaicas respecto a otras comarcas catalanas, la afectación no es menospreciable. Y más teniendo en cuenta los cambios en los usos y cubiertas del suelo en el Pirineo, que indican una tendencia clara hacia la continuidad de las masas forestales debido al abandono de las actividades tradicionales.

Los incendios en las comarcas de montaña de Cataluña se reparten por todo el territorio tal y como se puede observar en la figura 2. Se evidencia una concentración de incendios pequeños alrededor de la red viaria principal, e incendios de mayor dimensión en la comarca de la Val d'Aran en el extremo noroccidental. En el apartado siguiente analizaremos las condiciones en que se dan estos incendios.

Los incendios en Cataluña, en general, en el Pirineo y en cada una de las comarcas, en particular, en lo que se refiere a hectáreas quemadas y en número de incendios distribuidos según la estacionalidad, presentan las siguientes características:

1. En primer lugar, las diferencias internas entre las comarcas de montaña muestran comportamientos distintos por lo que respecta al número de incendios y la superficie quemada (Figura 3). Así, las comarcas con mayor número de incendios no son las que tienen una mayor superficie quemada. En este sentido, destaca la Val d'Aran que es la que ha visto arder más superficie, pero en cambio es una de las que tiene menos incendios. $\mathrm{Y}$ en el sentido contrario el Berguedà, que si bien aparece como la comarca con más puntos de ignición, es de las que ha quemado menos hectáreas.

2. Se observa una tendencia diferenciada entre Cataluña y las comarcas de montaña, por lo que se refiere a la estacionalidad, en cuanto a la superfície quemada y el número de incendios. En Cataluña el mayor número de hectáreas quemadas se dan durante el verano ( $78 \%$ de un total de 87.000 ha quemadas), mientras que en las comarcas de montaña, la mayor superficie quemada se da durante los meses de invierno (el 77\% de un total de más de 6.000 ha; Figuras 4 y 5 ).

3. En tercer lugar, la distribución de los incendios en Cataluña guarda relación con la estacionalidad. La estación con más incendios es el verano $(50 \%$ de los incendios) y coincide con la mayor superficie quemada. En el Pirineo, la diferencia respecto al número de incendios en verano e invierno es nula.

4. En Cataluña los meses con más incendios y superfície quemada son: julio, agosto y junio (ordenados de más a menos), mientras que en el Pirineo esto ocurre en febrero, enero, marzo y julio (ordenados de más a menos) (Figura 6, a y b). A partir del detalle de cada una de las comarcas (Figuras 7 y 8 ) observamos diferencias entre ellas en referencia a la estacionalidad, tanto por lo que respecta a la frecuencia de las igniciones como a la distribución de la superficie quemada asociada al punto de ignición.

\subsection{Los cambios en las cubiertas del suelo en las comarcas de montaña}

Para llegar a entender los cambios en los usos y las cubiertas del suelo en el Pirineo catalán y explicar cuáles son los factores que hacen que el territorio sea más vulnerable, es importante empezar por el análisis de estos cambios. A partir de los dos mapas de cubiertas homogeneizados se ha cuantificado la superficie de cada tipo de cubierta y para cada uno de los años (Tabla 1). 


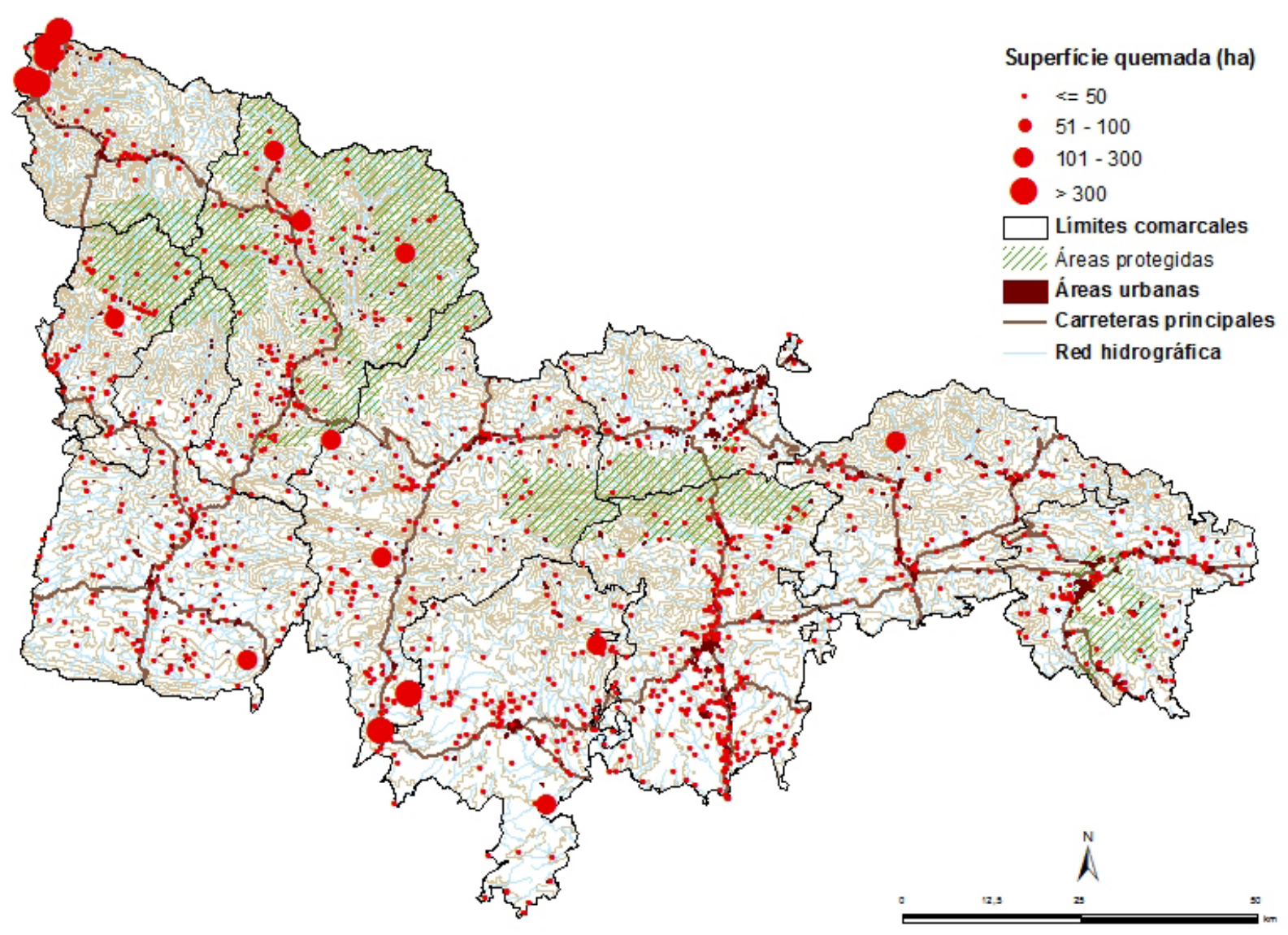

Figura 2: Distribución espacial de los incendios (1995-2008). Fuente: Elaboración propia a partir de los datos de la Generalitat de Catalunya.

Figure 2: Spatial distribution of fires (1995-2008).

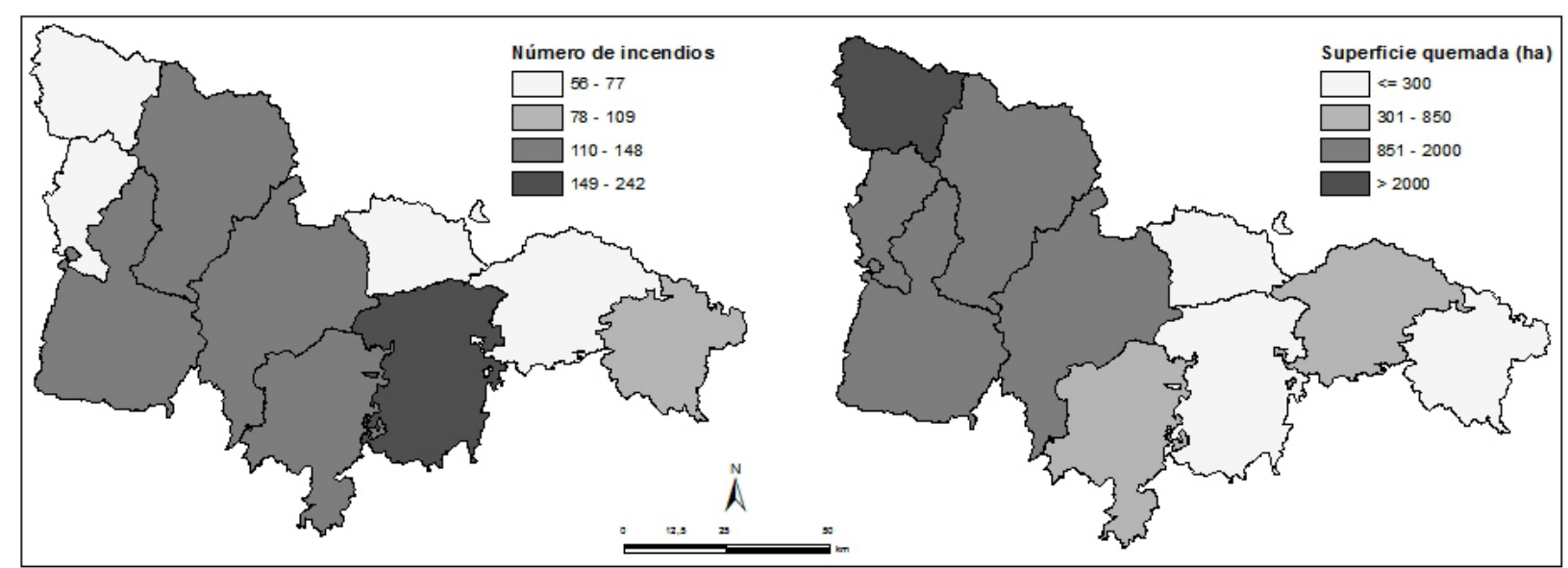

Figura 3: Distribución de los incendios y superficie quemada en las comarcas de montaña (1995-2008). Fuente: Elaboración propia a partir de los datos de la Generalitat de Catalunya.

Figure 3: Fires distribution and area burned in the mountain counties (1995-2008). 


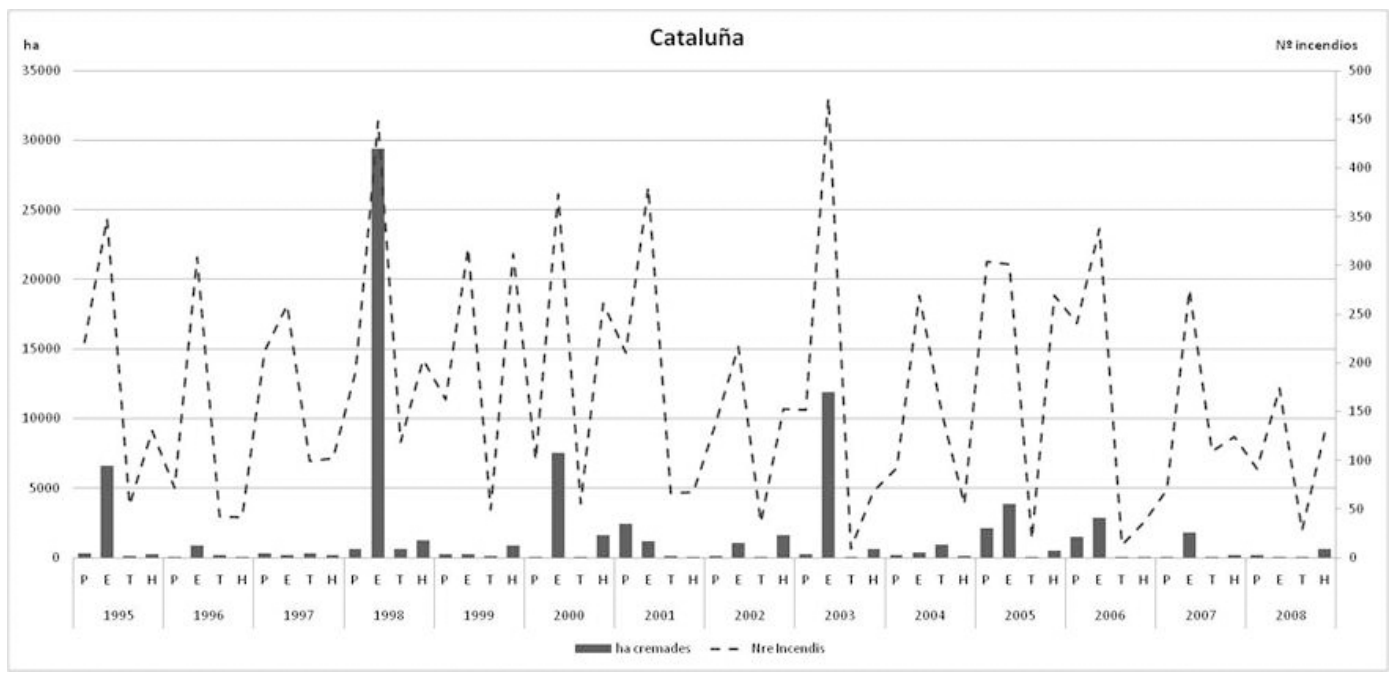

Figura 4: Incendios en Cataluña durante el período 1995-2008 según la estacionalidad. Fuente: Elaboración propia a partir de los datos de la Generalitat de Catalunya

Figure 4: Fires in Catalonia during 1995-2008 period according to seasonality.

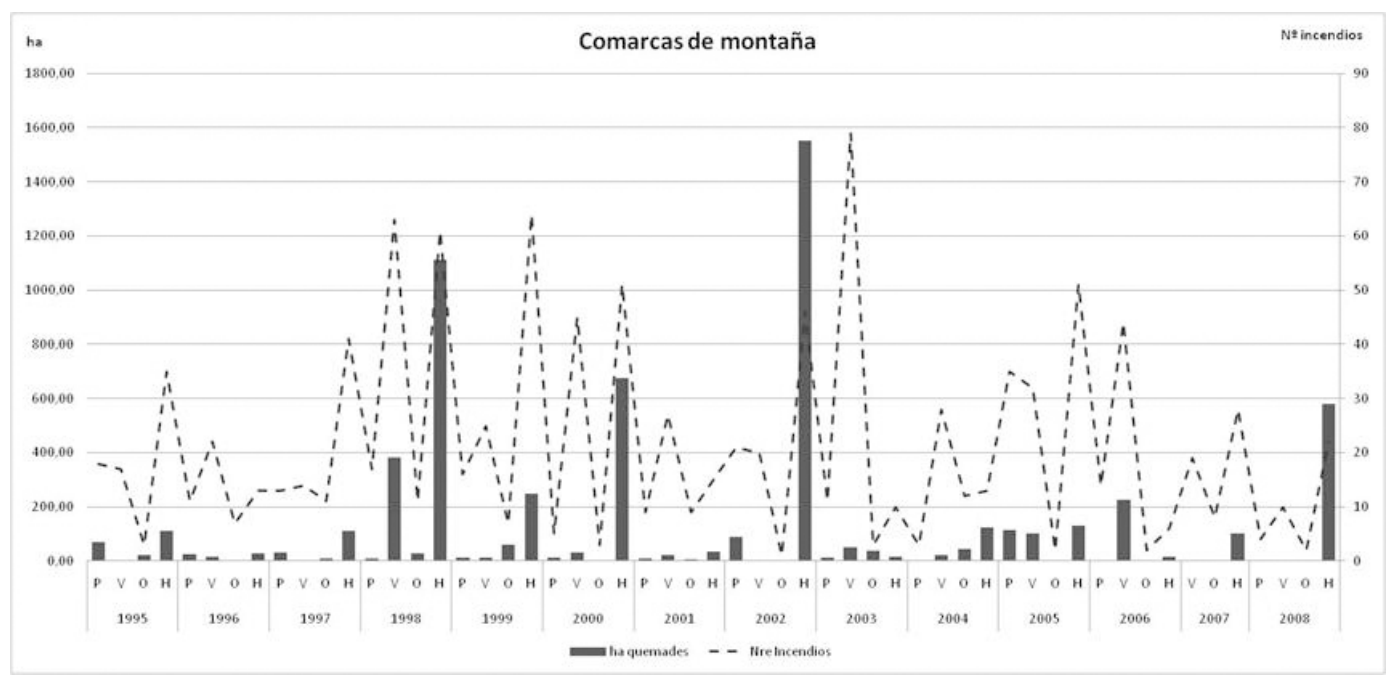

Figura 5: Incendios en las comarcas de montaña durante el período 1995- 2008 según la estacionalidad. Fuente: Elaboración propia a partir de los datos de la Generalitat de Catalunya.

Figure 5: Fires in mountain counties during 1995-2008 period according to seasonality.

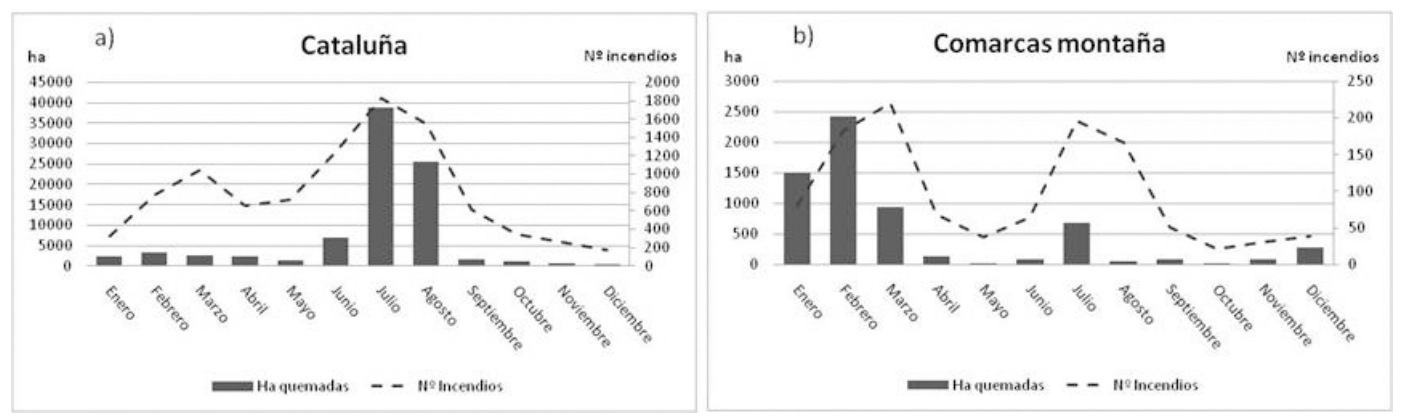

Figura 6: Número de incendios y superficie quemada en Cataluña y en los Pirineos por meses del año. Fuente: Elaboración propia a partir de los datos de la Generalitat de Catalunya.

Figure 6: Number of fires and area burned in Catalonia and the Pyrenees for months. 


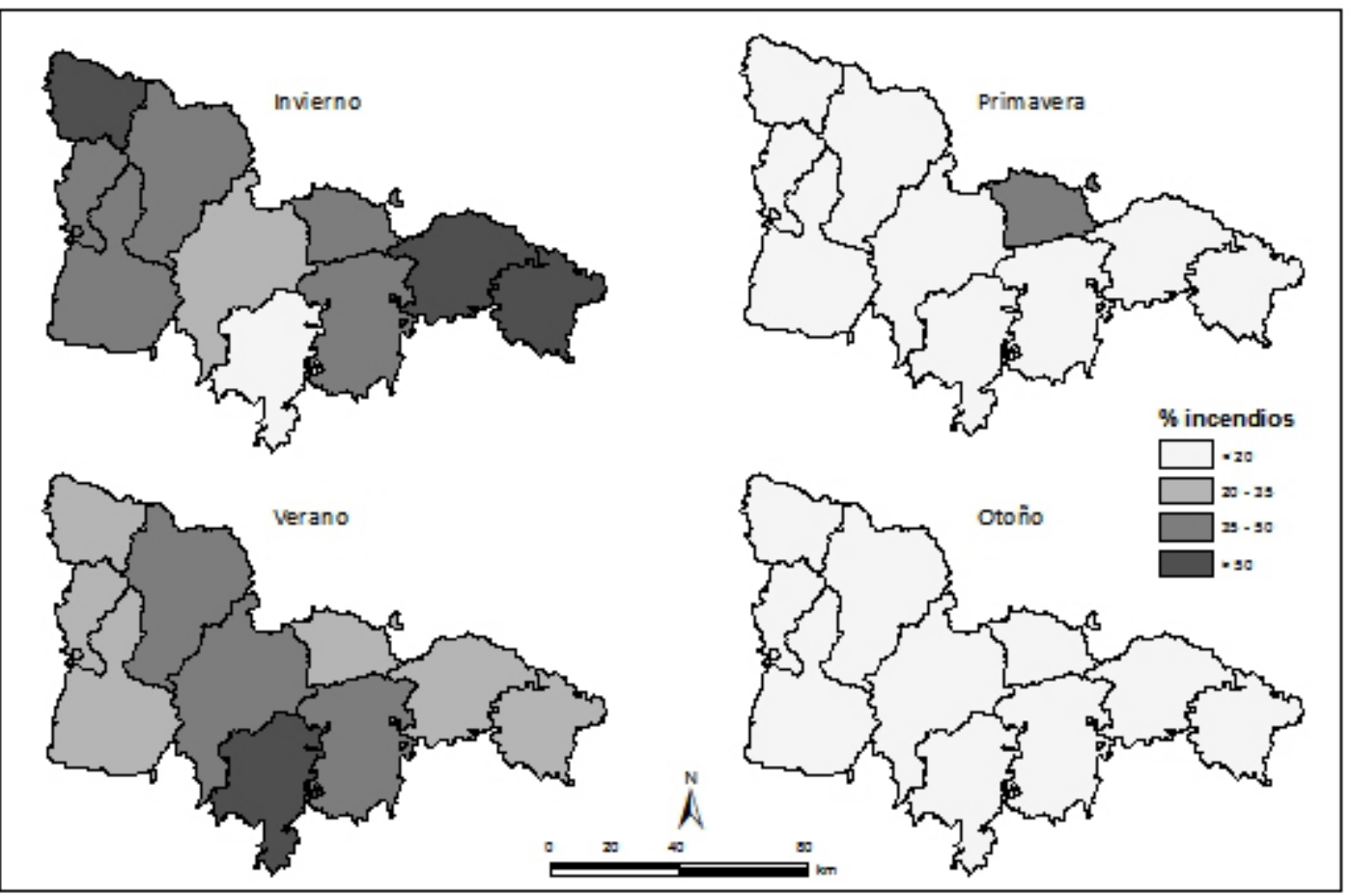

Figura 7: Frecuencia de incendios por comarcas y estacionalidad. Fuente: Elaboración propia de los datos de la Generalitat de Catalunya. Figure 7: Fire frequency by counties and seasonality.

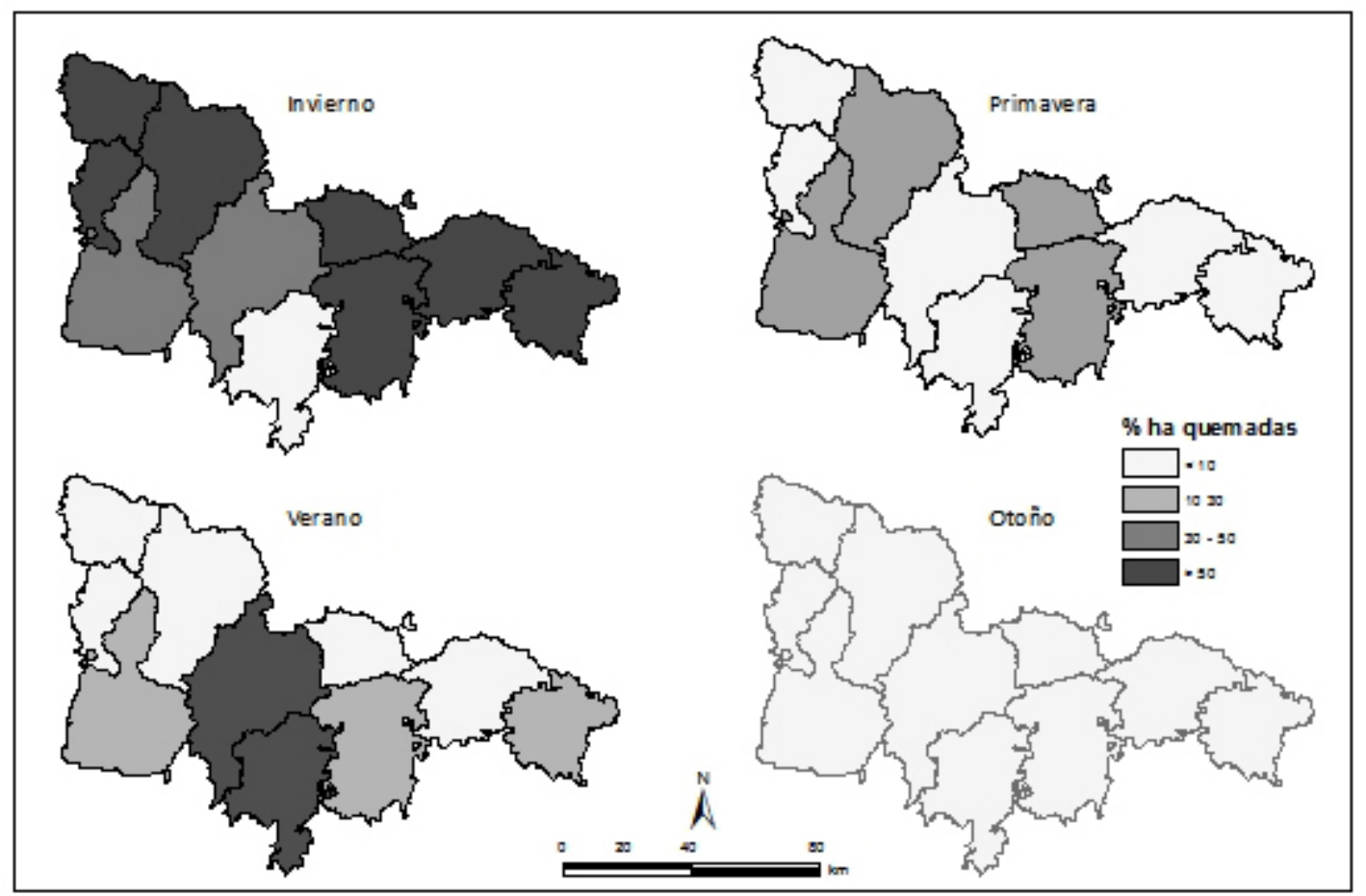

Figura 8: Distribución estacional de la superficie que quemaron los incendios de cada una de las comarcas. Fuente: Elaboración propia de los datos de la Generalitat de Catalunya.

Figure 8: Seasonal distribution of surface fires burned for each county. 
Tabla 1: Cuantificación de los usos del suelo del año 1993 y 2005-07.

Table 1: Quantification of land use land cover 1993 and 2005-07.

\begin{tabular}{|c|c|c|c|c|c|c|}
\hline \multirow{2}{*}{ Descripción } & \multicolumn{2}{|c|}{$\mathbf{1 9 9 3}$} & \multicolumn{2}{c|}{$\mathbf{2 0 0 5 - 0 7}$} & \multirow{2}{*}{ Diferencia (ha) } & $\begin{array}{c}\text { Diferencia } \\
\text { \% }\end{array}$ \\
\cline { 2 - 5 } & ha & $\mathbf{\%}$ & ha & \% & & 0,2 \\
\hline Bosque denso & $483.521,8$ & 50,1 & $485.730,5$ & 50,3 & $2.208,7$ & 3,7 \\
\hline Bosque claro & $9.903,7$ & 1,0 & $44.981,8$ & 4,7 & $35.078,1$ & $-0,5$ \\
\hline Matorral & $154.762,6$ & 16,0 & $149.080,5$ & 15,5 & $-5.682,1$ & 1,4 \\
\hline Prados y herbazales & $112.257,7$ & 11,6 & $125.879,2$ & 13,0 & $13.621,5$ & 0 \\
\hline Zonas quemadas & 5,4 & 0,0 & 67,7 & 0,0 & 62,3 & -5 \\
\hline Cultivos & $132.711,2$ & 13,8 & $84.480,6$ & 8,8 & $-48.230,6$ & $-0,2$ \\
\hline Zonas denudadas & 59.842 & 6,2 & $57.738,2$ & 6,0 & $-2.103,8$ & 0,1 \\
\hline Aguas & $4.440,9$ & 0,5 & $5.469,9$ & 0,6 & $1.029,0$ & 0,1 \\
\hline Urbano & $4.613,4$ & 0,5 & $9.084,1$ & 0,9 & $4.470,7$ & 0,4 \\
\hline
\end{tabular}

Fuente: Elaboración propia.

Tabla 2: Cambios en los usos y cubiertas del suelo en los Pirineos 1993 (columnas) y 2005 (filas) (\%).

Table 2: Land use land cover change in the Pyrenees 1993 (columns) and 2005 (rows) (\%).

\begin{tabular}{|l|c|c|c|c|c|c|c|c|c|}
\hline & $\begin{array}{c}\text { Bosque } \\
\text { denso }\end{array}$ & $\begin{array}{c}\text { Bosque } \\
\text { claro }\end{array}$ & Matorral & $\begin{array}{c}\text { Prados y } \\
\text { herbazales }\end{array}$ & $\begin{array}{c}\text { Zonas } \\
\text { quemadas }\end{array}$ & Cultivos & $\begin{array}{c}\text { Zonas } \\
\text { denudadas }\end{array}$ & Aguas & Urbano \\
\hline Bosque denso & 86,9 & 49,4 & 23,5 & 6,3 & 53,4 & 8,2 & 8,0 & 4,5 & 2,6 \\
\hline Bosque claro & 4,3 & 23,7 & 9,4 & 3,3 & 10,9 & 1,5 & 2,1 & 0,1 & 0,2 \\
\hline Matorral & 5,4 & 19,1 & 50,9 & 21,5 & 35,7 & 8,3 & 11,2 & 1,6 & 2,2 \\
\hline $\begin{array}{l}\text { Prados y } \\
\text { herbazales }\end{array}$ & 1,3 & 4,7 & 10,1 & 58,4 & 0,0 & 20,3 & 17,5 & 2,7 & 4,7 \\
\hline Zonas quemadas & 0,0 & 0,1 & 0,0 & 0,0 & 0,0 & 0,0 & 0,0 & 0,0 & 0,0 \\
\hline Cultivos & 1,0 & 0,6 & 1,1 & 0,5 & 0,0 & 57,9 & 0,4 & 0,1 & 4,0 \\
\hline Zonas denudadas & 0,8 & 2,2 & 4,5 & 9,5 & 0,0 & 0,6 & 58,8 & 2,6 & 0,7 \\
\hline Aguas & 0,1 & 0,0 & 0,1 & 0,1 & 0,0 & 0,1 & 0,8 & 87,9 & 0,7 \\
\hline Urbano & 0,1 & 0,1 & 0,2 & 0,3 & 0,0 & 2,6 & 0,8 & 0,4 & 82,2 \\
\hline
\end{tabular}

Fuente: Elaboración propia.

Las cifras de la tabla 1 no muestran unos cambios muy significativos durante estos 15 años evaluados, pero sí permiten evidenciar una cierta tendencia. Se trata de una zona donde predominan los bosques densos y, como se puede comprobar, los cambios más significativos se dan en zonas de bosque claro, con un incremento de 35.000 ha, y en el cultivo, que ha perdido poco más de 48.000 hectáreas. Estos son los cambios clásicos en el contexto de abandono del suelo en Cataluña y el mediterráneo en general (Badia et al., 2010; Turner et al., 2007).

Utilizando las herramintas SIG, se ha combinado analíticamente el mapa de cubiertas del suelo del año 1993 con el del año 2005-07; de esta manera es posible analizar en qué dirección han ido estos cambios y cuál es su localización exacta (Tabla 2).

Las columnas de la Tabla 2 corresponden a las cubiertas del año 1993, mientras que las filas corresponden al año 2005-07. Los datos muestran que durante estos
15 años ha habido un retroceso de las actividades relacionadas con la agricultura y el pastoreo, retroceso clásico y que supone una evidencia de la TF. El tipo de cubierta relacionada con las actividades agrícolas y ganaderas retrocede en beneficio del bosque. Por este motivo, hay un $20,3 \%$ de cultivos que pasan a prados y herbazales, al tiempo que los prados y herbazales se convierten en matorral y zonas denudadas, pero también hay un $23,5 \%$ de matorral que pasa a bosque denso y el bosque claro tiene una clara tendencia hacia el bosque denso (49\%). Se evidencia pues en el Pirineo el inicio de esta transición forestal que se ha introducido en apartados anteriores, pero este retroceso ha sido más tardío que en otros lugares de Cataluña. Actualmente se ve un proceso de transición, de agrícola y ganadero a matorral para convertirse en bosque claro y finalmente, el último estrato de la reforestación, bosque denso. Cabe destacar el $4,5 \%$ de cubierta de agua que pasa a bosque denso ${ }^{9}$, esta disminución podría explicarse por la densi-

\footnotetext{
${ }^{9}$ En el proceso de fotointerpretación de las imágenes de 2005-07 se detecta una menor superficie debido a que el bosque cubre parte de la superficie de aguas. Hecho que se ha relacionado con la densificación de la cubierta forestal. No se descarta tampoco algún tipo de error (fuentes originales, criterio de definición entre las zonas lacustres y las cubiertas forestales, etc.) que podría inducir a tal cambio pero que escapa de este trabajo.
} 


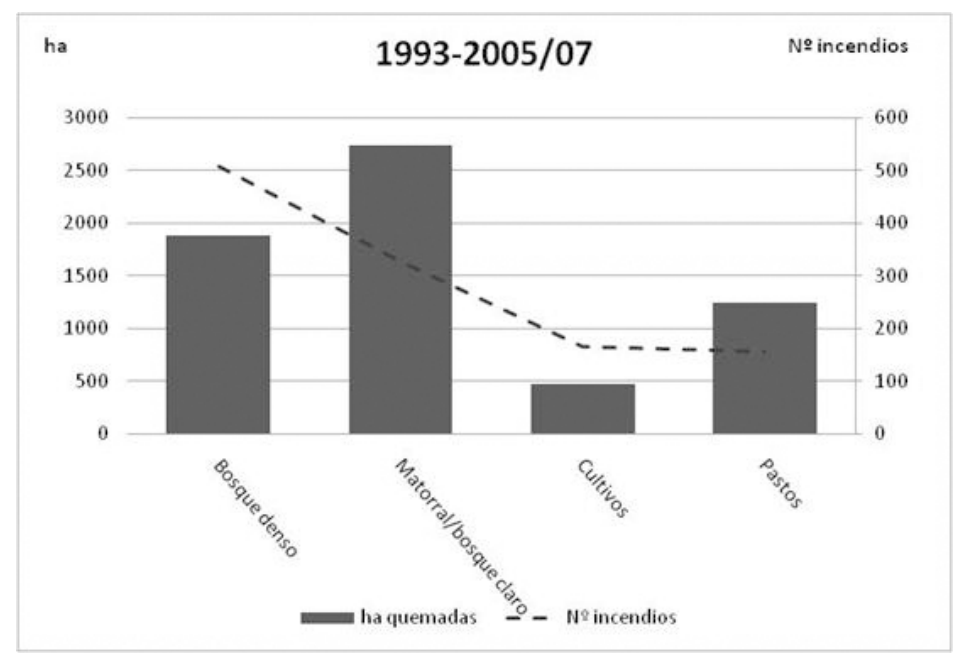

Figura 9: Número de incendios y superficie quemada según clasificación de las cubiertas. Fuente: Elaboración propia a partir del MCSC del CREAF.

Figure 9: Number of fires and area burned by cover classification.

ficación de la cubierta forestal. Aunque la cubierta urbanizada en el Pirineo es minoritaria (no llega al $1 \%$ en ninguno de los dos años) es necesario prestar atención a la incidencia que puede tener en estos cambios, basta fijarnos en el 2,6\%, de cultivos del año 1993 que pasan a urbano en el año 2005-07.

\subsection{Cambios en las cubiertas del suelo y la incidencia en los incendios forestales}

La transformación socioeconómica de las zonas de montaña ha provocado los cambios en las cubiertas analizados en el apartado anterior. El abandono de las actividades agrícolas y ganaderas ha comportado una reforestación del territorio y una rápida pérdida del conocimiento cultural alcanzado durante décadas sobre la gestión del territorio (Poyatos et al., 2003). En este sentido, el uso controlado del fuego tradicionalmente ha constituido una medida eficaz contra los incendios y puede emplearse tanto en una fase preventiva como en el ámbito de la extinción. En la fase preventiva, el uso controlado del fuego permite, entre otros, reducir el combustible vegetal en terrenos forestales permitiendo, al mismo tiempo, condicionar el comportamiento de un eventual incendio forestal de tal manera que se mantenga dentro de la capacidad de extinción de los servicios de prevención y extinción de incendios (DECRET 312/2006).

La superposición de cada uno de los puntos de ignición con diferentes variables territoriales permite obtener una tabla donde es posible ver para cada incendio el cambio de cubierta (1993-2005) donde ha tenido lugar, la altitud, la orientación y la pendiente. A partir del análisis se pueden apreciar las siguientes características: 1) más del $50 \%$ del Pirineo catalán es bosque el año 2005-07 y ya lo era el año 1993. 2) El 60\% de los incendios tuvieron lugar en bosques densos, en altitudes infe- riores a los 1.500 metros, en pendientes inferiores a $40^{\circ}$ $\mathrm{y}$ en una orientación predominantemente hacia el sur.

Para explicar mejor cómo se prenden los incendios en el Pirineo se han agrupado diferentes categorías de las cubiertas del suelo, con la finalidad de analizar el comportamiento de los incendios según si han tenido lugar en cubiertas más densas o más esclarecidas. Así pues, a partir del mapa de la combinación analítica de las cubiertas del año 1993 y las cubiertas del año 200507, se ha generado las siguientes categorías: Bosque denso, cultivos, matorrales/bosque claro y pastos. En la figura 9 se puede observar cómo el mayor número de incendios se localizan en zonas de bosque denso aunque los iniciados en zonas de matorral y bosque claro son los que queman una mayor superficie.

\subsection{Análisis de $\chi^{2}$}

El valor de $\chi^{2}$ calculado para las diferentes variables (Tabla 3) demuestra que los incendios están influenciados por las diferencias en la altitud, la orientación, la pendiente, el tipo de cubierta y la estacionalidad. En todos los casos el valor de $\chi^{2}$ valida las hipótesis de investigación.

Tabla 3: Cálculo de $\chi^{2}$.

Table 3: $\chi^{2}$ calculation.

\begin{tabular}{|c|c|c|c|c|}
\hline Variable & $\boldsymbol{\chi}^{\mathbf{2}}$ & $\begin{array}{c}\text { Valor } \\
\text { crítico }\end{array}$ & $\begin{array}{c}\text { Grados } \\
\text { de } \\
\text { libertad }\end{array}$ & $\begin{array}{c}\text { Nivel de } \\
\text { significación }\end{array}$ \\
\hline Altitud & 286,98 & 11,34 & 3 & 0,01 \\
\hline Orientación & 1084,12 & 20,09 & 7 & 0,01 \\
\hline Pendiente & 83,50 & 11,34 & 3 & 0,01 \\
\hline Cubiertas & 585,42 & 11,34 & 3 & 0,01 \\
\hline Estacionalidad & 109,40 & 49,96 & 3 & 0,01 \\
\hline
\end{tabular}

Fuente: elaboración propia. 
En el caso de la altitud, pendiente y las cubiertas, con 3 grados de libertad y un nivel de significación 0,01 , el valor crítico es de 11,34 , y se valida por lo tanto la hipótesis de investigación.

El valor de $\chi^{2}$ de la altitud es de 286,98 , muy superior al valor crítico; según la distribución de la superficie de los intervalos por altitud, esperaríamos más incendios en zonas superiores a $1.593 \mathrm{~m}$; en cambio en las zonas con altitudes inferiores, de $140 \mathrm{~m}$ a $656 \mathrm{~m}$ y de $657 \mathrm{~m}$ $1.045 \mathrm{~m}$ se esperarían menos incendios por la proporción de superficie, pero contrariamente hay más.

El valor de $\chi^{2}$ de la pendiente es de 83,50, hay diferencias entre las frecuencias observadas y las frecuencias esperadas aunque las diferencias entre intervalos no son tan acusadas como en otras variables; por intervalos hay un mayor número de incendios entre $0^{\circ}$ y $20^{\circ}$. En el caso de las cubiertas, con un $\chi^{2}$ de 585,4 , se esperarían más incendios en la categoría de bosque denso teniendo en cuenta la cantidad de superficie correspondiente a esta categoría. El matorral, en cambio, tiene más incendios de los que se esperaría.

El valor de $\chi^{2}$ de la orientación, de 1084,12, hace aceptar nuevamente la hipótesis de investigación; se esperarían menos incendios en orientaciones de Oeste y Noroeste de los que se observan en realidad y menos incendios en orientación Este.

Por último, la distribución de los incendios a lo largo del año no es homogénea sino que varía según la estacionalidad, así lo indica el valor de $\chi^{2}$ de 109,4; la estación con más incendios es invierno seguida a muy poca distancia del verano.

Se puede afirmar pues que los incendios en las comarcas de montaña durante el periodo de estudio tienen lugar en altitudes inferiores a $1.500 \mathrm{~m}$, en una pendiente inferior a $40^{\circ}$, en bosque denso, aunque más del $50 \%$ de la superficie del territorio estudiado pertenece a esta categoría, y matorral (donde hay más incendios de los esperados) y en orientaciones de Este, Sur, Sureste y Suroeste.

\section{Conclusiones}

En este artículo se han aportado algunos argumentos para responder a la pregunta de investigación planteada inicialmente ¿qué ha cambiado en el Pirineo para que los incendios actualmente constituyan un riesgo? Además se aportan datos que permiten validar la hipótesis de partida de que los incendios en las comarcas de montaña siguen una dinámica distinta en cuanto a la estacionalidad respecto al conjunto de Cataluña. La caracterización de los incendios en cuanto a la orientación, la altitud y los cambios en las cubiertas del suelo permiten afirmar que hay algunas zonas más vulnerables a los incendios que otras. Faltarían datos de varios años más para poder ajustar resultados, pero a pesar de ello se pueden apuntar algunos factores de cambio y las consecuencias de estos cambios que hacen las comarcas de montaña de Cataluña más vulnerables a los incendios. A pesar de ello podemos afirmar que:

a. El número de incendios de invierno es ligeramente superior al de verano.

b. En invierno se quema cinco veces más de superfície que en verano

c. Se está dando una transición forestal que tiende hacia un tipo de cubierta de bosque denso. Se trata de un proceso muy lento porque la mayor parte de los incendios y la mayoría de superfície quemada se da en matorral y bosque claro, con lo que se retrasa la transición a bosque denso.

d. Las zonas de bosque denso son las que tienen menos puntos de ignición por lo que la consolidación del bosque denso debería disminuir la vulnerabilidad.

e. Los cambios en las cubiertas y los usos del suelo describen un paisaje más homogéneo, lo cual incrementa la vulnerabilidad del territorio frente a los incendios forestales. El mosaico agrosilvopastoral-forestal favorece la discontinuidad de las masas forestales y supone líneas de ruptura en caso de incendio forestal.

\section{Agradecimientos}

El presente trabajo se ha realizado en el marco de los siguientes proyectos: Geografia Aplicada (2009SGR0106) Generalitat de Catalunya. Los paisajes de las áreas de montaña. Patrones de gestión y de ocupación del territorio (CSO2009-08271), Ministerio de Ciencia e Innovación. Harmonished European Land Monitoring (FP7-261562-HELM), Comisión Europea.

\section{Referencias}

Antrop, A., 2006. Sustainable landscapes: contradiction, fiction or utopia?. Landscape and Urban Planning, 75(3-4): 187-197. http://dx.doi.org/10.1016/j.landurbplan.2003.10.002.

Asociación Mundial sobre el Fuego, 2004. El Fuego, los Ecosistemas y la Gente. Una evaluación preliminar del fuego como un tema global de conservación. The nature Conservancy. Saving the last great on earth. Iniciativa Global para el Manejo del Fuego Octubre de 2004

Badia, A., Estany, G., Otero, I. \& Boada, M., 2010. Estudio del crecimiento urbano disperso y cambios en el paisaje en Matadepera (Región Metropolitana de Barcelona). Boletín de la Asociación de Geógrafos Españoles, 54: 301-321.

Benayas, J., Muñoz, M. García-Ventura, D., Tejedo, P., Díaz-González, M. J., Asensio, M \& de Esteban, A., 2007. Análisis de los modelos de uso público de la red de Parques Nacionales. Proyectos de investigación en Parques Nacionales 2003-2006. Organismo Autónomo de Parques Nacionales: 7-28 pp.

CREAF, 2010. Interpretació de les llegendes de les diferents edicions del Mapa de Cobertes del Sol de Catalunya. Bellaterra (Cerdanyola del Vallès).

Chowdhury, R.R. \& Moran F.E., 2012. Turning the curve: A critical review of Kuznets approaches. Applied Geography, 32(1): 3-11. http://dx.doi.org/10.1016/j.apgeog.2010.07.004. 
Council of Europe. The European Landscape Convention. http:// www.coe.int/t/dg4/cultureheritage/heritage/Landscape/default_en.asp [Último acceso 11/04/2014]

Cunill, R., Soriano, J.M., Bal, M.C., Pèlachs, A., Rodríguez, J.M., \& Pérez-Obiol, R., 2013. Holocene high-altitude vegetation dynamics in the Pyrenees: A pedoanthracology contribution to an interdisciplinary approach. Quaternary International, 289: 60-70. http://dx.doi.org/10.1016/j.quaint.2012.04.041.

DECRET 312/2006, de 25 de juliol, pel qual es regula la gestió del foc tècnic per part del personal dels serveis de prevenció i extinció d'incendis de la Generalitat de Catalunya DOGC núm. 4685, 13.07.06. http://www.upf.edu/sintesi/2006/dj312.htm [Último acceso 15/07/2013]

Hewitt, K., 1997. Regions of risk, London, Longman.

Lambin, E.F. \& Meyfroidt, P., 2010. Land use transitions: Socio-ecological feedback versus socio-economic change. Land Use Policy, 27(2): 108-118. http://dx.doi.org/10.1016/ j.landusepol.2009.09.003.

Lasanta-Martínez, T., González-Hidalgo, J.C. Vicente-Serrano, S.M. \& Sferi, E., 2006. Using landscape ecology to evaluate an alternative management scenario in abandoned Mediterranean mountain areas. Landscape and Urban Planning, 78(1-2): 101-114. http://dx.doi.org/10.1016/j.landurbplan.2005.06.003.

Lasanta-Martínez, T., Vicente-Serrano, S. \& Cuadrat-Prats, J.M., 2005. Mountain Mediteranean landscape evolution caused by abandonament of traditional primary activities: a study of Spanish Central Pyreenees. Applied Geography, 25: 47-65. http:// dx.doi.org/10.1016/j.apgeog.2004.11.001.

LLEI 2-1983, de 9 de març, llei d'alta muntanya, DOGC, 312, 16.03.1983.

LUCC, Land Use Land Cover Change project. http://www. globallandproject.org/ [Ultimo acceso 11/04/2014]

Mapa de Cobertes del Sòl de Catalunya (MCSC), (2005-07). http://www.creaf.uab.es/mcsc/ [Último acceso 11/04/2014]

Miller, F., Osbahr, H., Boyd, E., Thomalla, F., Bharwani, S., Ziervogel, G., Walker, B., Birkmann, J., Van der Leeuw, S., Rockström, J., Hinkel, J., Downing, T., Folke, C. \& Nelson, D., 2010. Resilience and vulnerability: complementary or conflicting concepts?. Ecology and Society. 15(3): 11. URL: http:// www.ecologyandsociety.org/vol15/iss3/art11/

Millington, J. D. A., 2007. Modelling Land-Use/Cover Change and Wildfire Regimes in a Mediterranean Landscape. $\mathrm{PhD}$ Thesis, Department of Geography. London, King's College London.

Moreira, F., Viedma, O., Arianoutsou, M., Curt, T., Koutsias, N., Rigolot, F., Barbati, A., Corona, P., Vaz, P., Xanthopoulos, G., Mouillot, F. \& Bilgili, E., 2011. Landscape - wildfire interactions in southern Europe: Implications for landscape management. Journal of Environmental Management 92(10): 2389-2402. http://dx.doi.org/10.1016/j.jenvman.2011.06.028.
Ninyerola, M., Pons, X. \& Roure, J.M., 2000. A methodological approach of climatological modelling of air temperature and precipitation through GIS techniques. International Journal of Climatology, 20(14): 1823-1841. http://dx.doi.org/10.1002/ 1097-0088(20001130)20:14<1823::AID-JOC566

Plana, E., 2011. Integració del risc d'incendis en la planificació forestal estratégica i l'ordenació del territori. Treballs de la Societat Catalana de Geografia, 71-72: 69-91.

Poyatos, R., Latron, J. \& Llorens, P., 2003. Land Use and Land Cover Change After Agricultural Abandonment: The Case of a Mediterranean Mountain Area (Catalan Pre-Pyrenees). Mountain Research and Development, 23(4): 362-368. http://dx.doi.org/ 10.1659/0276-4741(2003)023[0362:LUALCC]2.0.CO;2.

Pyne, S.J., 1996. Introduction to wildland fire, John Wiley and Sons. Rudel, T.K., Coomes, O.T., Moran, E., Achard, F., Angelsen, A., $\mathrm{Xu}$, J. \& Lambin, E., 2005. Forest transitions: towards a global understanding of land use change. Global environmental change, 15(1): 23-31. http://dx.doi.org/10.1016/j.gloenvcha.2004.11.001.

Rudel, T.K., Schneider, L. \& Uriarte, M., 2010. Forest transition: an introduction. Land Use Policy, 27(2): 95-97. http://dx.doi.org/ 10.1016/j.landusepol.2009.09.021

Schröter, D., Cramer, W., Leemans, R., Prentice, I.C., Araújo, M.B., Arnell, N.W., Bondeau, A., Bugmann, H., Carter, T.R., Garcia, C.A., de la Vega- Leinert, A.C., Erhard, M., Ewert, F., Glendining, M., House, J.I., Kankaanpää, S., Klein, R.J.T., Lavorel, S., Lindner, M., Metzger, M.J., Meyer, J., Mitchell, T.D., Reginster, I., Rounsevell, M., Sabaté, S., Sitch, S., Smith, B., Smith, J., Smith, P., Sykes, M.T., Thonicke, K., Thuiller, W., Tuck, G., Zaehle, S. \& Zierl, B., 2005. Ecosystem Service Supply and Human Vulnerability to Global Change in Europe. Science, 310: 1333-1337. http://dx.doi.org/10.1126/science. 1115233

Turner, B.L., Lambin, E. F. \& Reenberg, A., 2007. The emergence of land change science for global environmental change and sustainability. Proceedings of the National Academy of Science USA, 104(52), 20666-20671. http://dx.doi.org/10.1073/pnas. 0704119104

Turner, B.L. \& Robbins, P., 2008. Land-Change Science and Political Ecology: similarities, differences, and implications for sustainability Science. Annual Review of Environmental Resources, 33: 295-316. http://dx.doi.org/10.1146/annurev. environ.33.022207.104943

Vélez, R., 1986. Incendios forestales y su relación con el medio rural. Estudios Agro-Sociales, 136: 195-224.

Vera, A., Badia, A. \& Tulla, A.F., 2011. Desarrollo local en el Pirineo Catalán: impulso económico y uso sostenible del territorio. Finisterra. Revista Portuguesa de Geografia, XLVI, 92: 9-27. 